\title{
Protective Mechanism of KIOM-4 in Streptozotocin-Induced Pancreatic $\beta$-Cells Damage Is Involved in the Inhibition of Endoplasmic Reticulum Stress
}

\author{
Rui Zhang, ${ }^{1}$ Jin Sook Kim, ${ }^{2}$ Kyoung Ah Kang, ${ }^{1}$ Mei Jing Piao, ${ }^{1}$ Ki Cheon Kim, ${ }^{1}$ \\ and Jin Won Hyun ${ }^{1}$ \\ ${ }^{1}$ School of Medicine, Jeju National University, Jeju-si 690-756, Republic of Korea \\ ${ }^{2}$ Diabetic Complication Research Center, Division of Traditional Korean Medicine Integrated Research, \\ Korea Institute of Oriental Medicine, Daejeon 305-811, Republic of Korea \\ Correspondence should be addressed to Jin Won Hyun, jinwonh@jejunu.ac.kr
}

Received 19 June 2010; Accepted 27 August 2010

Copyright (c) 2011 Rui Zhang et al. This is an open access article distributed under the Creative Commons Attribution License, which permits unrestricted use, distribution, and reproduction in any medium, provided the original work is properly cited.

\begin{abstract}
Endoplasmic reticulum stress-mediated apoptosis plays an important role in the destruction of pancreatic $\beta$-cells and contributes to the development of type 1 diabetes. The present study examined the effect of KIOM-4, a mixture of four plant extracts, on streptozotocin- (STZ-) induced endoplasmic reticulum (ER) stress in rat pancreatic $\beta$-cells (RINm5F). KIOM-4 was found to inhibit STZ-induced apoptotic cell death, confirmed by formation of apoptotic bodies and DNA fragmentation. STZ was found to induce the characteristics of ER stress; mitochondrial $\mathrm{Ca}^{2+}$ overloading, enhanced ER staining, release of glucose-regulated protein 78 (GRP78), phosphorylation of RNA-dependent protein kinase (PKR) like ER kinase (PERK) and eukaryotic initiation factor- $2 \alpha$ (eIF- $2 \alpha$ ), cleavage of activating transcription factor 6 (ATF6) and caspase 12, and upregulation of CCAAT/enhancerbinding protein-homologous protein (CHOP). However, KIOM-4 attenuated these changes induced by STZ. Furthermore, KIOM4 suppressed apoptosis induced by STZ in CHOP downregulated cells using CHOP siRNA. These results suggest that KIOM-4 exhibits protective effects in STZ-induced pancreatic $\beta$-cell damage, by interrupting the ER stress-mediated pathway.
\end{abstract}

\section{Introduction}

KIOM-4 is a combination of extracts obtained from Magnolia officinalis, Pueraria lobata, Glycyrrhiza uralensis, and Euphorbia pekinensis. Magnolia officinalis exhibits anticancer, antimutagenic, hepatoprotective, neuroprotective, antiinflammatory and antimicrobial activities [1-7]. Pueraria lobata possesses antiatherogenic, antimutagenic, antidiabetic, and antioxidant properties [8-11]. Glycyrrhiza uralensis possesses detoxifying, antioxidant [12], antiulcer, antiinflammatory, antiviral, antiatherogenic, anticarcinogenic properties [13], and cytoprotective effect against hepatotoxicity [14]. Euphorbia pekinensis is widely distributed in northeast mainland China and its roots have been used as traditional folk medicine for the treatment of edema, and shown to possess antiviral and cytotoxic properties $[15,16]$. We recently demonstrated that KIOM-4 exhibits cytoprotective effects against streptozotocin- (STZ-) induced oxidative stress damage in $\beta$-cells through catalase activation
[17] and heme oxygenase-1 [18], and protects cells against STZ-induced mitochondrial damage in pancreatic $\beta$-cells through its antioxidant properties [19].

Type 1 diabetes results from autoimmune and/or inflammatry processes that selectively disrupt insulin-producing pancreatic $\beta$-cell, and is characterized by hyperglycemia due to reduced insulin secretion. Apoptosis is considered to be the main mode of pancreatic $\beta$-cell death in diabetes $[20,21]$. One of the characteristic features of $\beta$-cells is a highly developed endoplasmic reticulum (ER), apparently due to heavy engagement in insulin secretion, as the early steps of insulin biosynthesis occur in the ER [22, 23]. ER is the site for folding and assembling proteins, lipid biosynthesis, vesicular traffic, and cellular calcium storage, and is sensitive to alterations in homeostasis. Proper ER function is essential to cell survival and perturbation of its function induces cellular damage and results in apoptosis. Various conditions can disturb ER functions and these conditions include inhibition of protein glycosylation, reduction of 
disulfide bond formation, calcium depletion from the ER lumen, impairment of protein transport from the ER to the Golgi apparatus, and expression of misfolded proteins. Such dysfunction causes proteotoxicity in the ER, collectively termed ER stress [24-26]. Recent studies suggest that ER stress plays an important role in the loss of $\beta$-cells [26-28]. Given that ER is a unique oxidizing folding-environment that favors disulfide bond formation, any change in cell redox state can triggers ER stress and parallel antioxidants protect cells from ER stress [29]. Furthermore, it has been suggested that the accumulation of misfolded protein within the lumen of the ER leads to ER stress, which in turn causes oxidative stress and finally cell death [30]. Recent research also revealed that antioxidants, such as butylated hydroxyanisole, could reduce ER stress [31]. Therefore, in present study, we hypothesized that the cytoprotective mechanism of KIOM-4 against STZ-induced pancreatic $\beta$ cells damage may be involved in interrupting ER stressmediated apoptotic pathway.

\section{Materials and Methods}

2.1. Preparation of KIOM-4. The KIOM-4 was provided by Jin Sook Kim PhD of the Korea Institute of Oriental Medicine (Daejeon, Korea). It was dissolved in dimethyl sulfoxide (DMSO), the final concentration of which did not exceed $0.1 \%$.

2.2. Reagents. STZ was purchased from Calbiochem (San Diego, CA). Hoechst 33342 and [3-(4,5-dimethylthiazol2-yl)-2,5-diphenyltetrazolium] bromide (MTT) were purchased from Sigma Chemical Company (St. Louis, MO). ER-Tracker Blue-White DPX and Rhod-2 acetoxymethyl ester (Rhod-2 AM) were purchased from Molecular Probes (Eugene, OR). Anti-CCAAT/enhancer-binding proteinhomologous protein (CHOP), -capsase 12, -activating transcription factor 6 (ATF6), and $\beta$-actin antibodies were purchased from Cell Signaling Technology (Beverly, MA). Antiphospho eukaryotic initiation factor- $2 \alpha$ (eIF-2 $\alpha$ ), glucose-regulated protein 78 (GRP78), and phospho-RNAdependent protein kinase (PKR) like ER kinase (PERK) antibodies were purchased from Santa Cruz Biotechnology (Santa Cruz, CA). The other chemicals and reagents were of analytical grade.

2.3. Cell Culture. RINm5F rat pancreatic $\beta$-cells were maintained at $37^{\circ} \mathrm{C}$ in an incubator with a humidified atmosphere of $5 \% \mathrm{CO}_{2}$, and cultured in RPMI 1640 medium containing $10 \%$ heat-inactivated fetal calf serum, streptomycin $(100 \mu \mathrm{g} / \mathrm{mL})$, and penicillin (100 units $/ \mathrm{mL})$.

2.4. Cell Viability Assays. Cells were seeded in a 96 well plate at a concentration of $1 \times 10^{5}$ cells $/ \mathrm{mL}$ and were treated with KIOM-4 at $50 \mu \mathrm{g} / \mathrm{mL}$. After 1 hour, $10 \mathrm{mM}$ of STZ was added, and the mixture was incubated for 24 hours. Fifty $\mu \mathrm{L}$ of the MTT stock solution $(2 \mathrm{mg} / \mathrm{mL})$ was then added into each well to attain a total reaction volume of $200 \mu \mathrm{L}$. After incubating for 4 hours, the plate was centrifuged at $800 \times g$ for 5 minutes, and the supernatants were aspirated. The formazan crystals in each well were dissolved in $150 \mu \mathrm{L}$ of DMSO and read at $\mathrm{A}_{540}$ on a scanning multiwell spectrophotometer [32, 33].

2.5. Nuclear Staining with Hoechst 33342. Cells were placed in a 24 well plate at $2 \times 10^{5}$ cells/well. At 16 hours after plating, cells were treated with $50 \mu \mathrm{g} / \mathrm{mL}$ of KIOM-4 and after further incubation for 1 hour, $10 \mathrm{mM} \mathrm{STZ} \mathrm{was}$ added to the culture. After 24 hours, $1.5 \mu \mathrm{L}$ of Hoechst 33342 (stock $10 \mathrm{mg} / \mathrm{mL}$ ), a DNA-specific fluorescent dye, was added to each well (final $15 \mu \mathrm{g} / \mathrm{mL}$ ) and incubated for 10 minutes at $37^{\circ} \mathrm{C}$. The stained cells were then observed under a fluorescent microscope, which was equipped with a CoolSNAP-Pro color digital camera, to examine the extent of nuclear condensation.

2.6. DNA Fragmentation. Cellular DNA fragmentation was assessed by cytoplasmic histone-associated DNA fragmentation kit from Roche Diagnostics (Mannheim, Germany) according to the manufacturer's instructions.

2.7. Mitochondrial $\mathrm{Ca}^{2+}$ Measurements. Rhod-2 AM probe was used to determine mitochondrial $\mathrm{Ca}^{2+}$ level [34]. Rhod-2 AM has a net positive charge, which facilitates its sequestration into mitochondria due to membrane potential-driven uptake. The use of Rhod-2 AM enhances the selectivity for mitochondrial loading, because this dye exhibits $\mathrm{Ca}^{2+}$ dependent fluorescence only after it is oxidized, and this occurs preferentially within the mitochondria. Cells were seeded in a 6 well plate at $1 \times 10^{5}$ cells $/ \mathrm{mL}$ and were treated with KIOM-4 at $50 \mu \mathrm{g} / \mathrm{mL}$. After 1 hour, $10 \mathrm{mM}$ of STZ was added, and the mixture was incubated for 24 hours. Cells were harvested, washed, and suspended in PBS containing Rhod-2 AM $(1 \mu \mathrm{M})$. After 15 minutes of incubation at $37^{\circ} \mathrm{C}$, the cells were washed, suspended in PBS, and analyzed by flow cytometry.

2.8. Fluorescent Microscopy and Staining. Image analysis for ER staining was achieved by seeding cells on a cover-slip loaded six well plate at $1 \times 10^{5}$ cells $/ \mathrm{mL}$. Sixteen hours after plating, cells were treated with KIOM-4. One hour following KIOM-4 treatment, STZ at $10 \mathrm{mM}$, thapsigargin at $2 \mu \mathrm{g} / \mathrm{mL}$, or tunicamycin at $2 \mu \mathrm{g} / \mathrm{mL}$ was added to the plates, respectively. Twenty four hours later, ER-Tracker BlueWhite DPX probe was added to the cells and incubated for 30 minutes under the same growth conditions. The loading solution was removed and cells were then washed with PBS. Microscopic images were collected using the Laser Scanning Microscope 5 PASCAL program (Carl Zeiss, Jena, Germany) on a confocal microscope.

2.9. Western Blot Analysis. Aliquots of the lysates ( $40 \mu \mathrm{g}$ of protein) were boiled for 5 minutes and electrophoresed on a $10 \%$ SDS-polyacrylamide gel. Blots in the gels were transferred onto nitrocellulose membranes (Bio-Rad, Hercules, CA), which were then incubated with primary antibodies. The membranes were further incubated with secondary 
antibody-horseradish peroxidase conjugates (Pierce, Rockland, IL), and exposed to X-ray film. Protein bands were detected using an enhanced chemiluminescence Western blotting detection kit (Amersham, Little Chalfont, Buckinghamshire, UK).

2.10. Transient Transfection of Small RNA Interference (siRNA). Cells were seeded at $1.5 \times 10^{5}$ cells/well in 24 well plate and allowed to reach approximately $50 \%$ confluence on the day of transfection. The siRNA construct used was obtained as mismatched siRNA control (siControl, Santa Cruz Biotechnology, Santa Cruz, CA) and siRNA against CHOP (siCHOP, Bioneer Corporation, Bioneer, South Korea). Cells were transfected with 10-50 nM siRNA using lipofectamineTM 2000 (Invitrogen, Carlsbad, CA) according to the manufacturer's instruction. At 24 hours after transfection, cells were treated with or without KIOM4 and/or STZ for 24 hours and examined by Hoechst 33342 staining and DNA fragmentation, respectively.

2.11. Statistical Analysis. All the measurements were made in triplicate and all values are represented as the mean \pm standard error of the mean (SEM). Data were subjected to an analysis of the variance (ANOVA) using the Tukey test to analyze the difference. $P<.05$ was considered statistically significant.

\section{Results}

3.1. Attenuated Characteristics of Apoptosis in RINm5F Cells Exposed to STZ by KIOM-4 Treatment. To investigate the potential role of KIOM-4 on STZ induced $\beta$-cells damage, we first examined the effects of KIOM-4 on cell survival. As shown in Figure 1(a), KIOM-4 significantly inhibited STZinduced cell damage. In addition, apoptosis was determined by morphological microscopy after staining of cellular nuclei with Hoechst 33342. The microscopic images in Figure 1(b) indicate that the control cells retained intact nuclei, while STZ-treated cells showed significant nuclear fragmentation, which is characteristic of apoptosis, while KIOM-4 reduced it. STZ dramatically increased the levels of DNA fragmentation compared to control, while KIOM-4 treatment attenuated STZ-induced DNA fragmentation (Figure 1(c)). Taken together, these results indicate that KIOM-4 protects cell viability by inhibiting STZ- induced apoptosis.

3.2. Reduction of STZ-Induced Mitochondrial $\mathrm{Ca}^{2+}$ Overloading and ER Stress by KIOM-4 Treatment. Depletion of ER calcium stores can induce ER stress [35], which leads to an increase in mitochondrial $\mathrm{Ca}^{2+}[36]$. We assessed the effects of KIOM-4 on mitochondrial $\mathrm{Ca}^{2+}$ mobilization. As shown in Figure 2(a), STZ treatment resulted in a significant increase in mitochondrial $\mathrm{Ca}^{2+}$ levels at 24 hours, while KIOM-4 treatment reduced STZ-induced mitochondrial $\mathrm{Ca}^{2+}$ overloading. Thapsigargin, which selectively inhibits the $\mathrm{Ca}^{2+}$-ATPase responsible for $\mathrm{Ca}^{2+}$ accumulation of ER, and tunicamycin, which blocks $\mathrm{N}$-linked protein glycosylationare, are well known for their capacity to induce ER stress [37, 38]. Recently, ER stress by thapsigargin has been shown to increase fluorescent intensity of the dye following ER staining with ER-Tracker Blue-White DPX [39]. KIOM-4 significantly attenuated the staining intensity of this dye increased by STZ treatment (Figure 2(b)). In our study, KIOM-4 also reduced the fluorescent intensity of ER staining, which is induced by thapsigargin (Figure 2(c)), while KIOM-4 did not show the capacity to reduce the fluorescent intensity increased by tunicamycin (data not shown).

Increased PERK phosphorylation and upregulation of GRP78 are major indicators of ER stress [35]. eIF-2 $\alpha$ is phosphorylated by PERK in response to ER stress, leading to attenuation of translational initiation and protein synthesis $[40,41]$. Therefore, we examined whether the effects of KIOM- 4 on STZ-induced $\beta$-cell damage is associated with the GRP78 and PERK/eIF- $2 \alpha$ kinase signaling pathway. STZ treatment induced a dramatic increase in GRP78, phosphorylated PERK and eIF- $2 \alpha$ levels, and KIOM- 4 attenuated these changes (Figure 3). Another hallmark of ER stress responses include ATF6 activation (cleaved form of ATF6) and subsequent induction of CHOP [42, 43]. STZ enhanced ATF6 activation and induced $\mathrm{CHOP}$ expression, while KIOM-4 abolished these changes (Figure 3). Caspase 12 has been reported to become activated during ER stress [35]. KIOM-4 treatment also attenuated STZ induced activation of caspase 12 (cleaved form of caspase 12) following ER stress (Figure 3). These results suggest that ER stress-mediated apoptosis was involved in the STZ-treated cells, and KIOM-4 inhibited these changes.

\subsection{Suppression of Cell Death Induced by STZ in CHOP Downregulated Cells by KIOM-4 Treatment. CHOP is reported to play a proapoptotic role during ER stress [42]. To investigate whether CHOP is directly involved in STZ- induced apoptosis, we employed siRNA against $\mathrm{CHOP}$ mRNA. As shown in Figures 4(a) and 4(b), suppressed $\mathrm{CHOP}$ expression were shown to further alleviate apoptotic phenomena in STZ-treated or KIOM-4 plus STZ-treated siCHOP cells, compared to STZ-treated or KIOM-4 plus STZ-treated siControl cells. These results suggest that CHOP may be in part involved in STZ-induced apoptosis which is mediated by ER stress pathway.}

\section{Discussion}

ER stress plays a key role in the pathogenesis of diabetes, contributing to pancreatic $\beta$-cell loss and insulin resistance [20]. Baseline of ER stress in $\beta$-cells is higher than in other cell types, because of their exposure to frequent energy fluctuations and the early steps of insulin biosynthesis occur in ER $[22,23]$. Numerous studies have reported that antioxidant treatment, which targets oxidative stress, may help prevent or delay the development of diabetes and its complications [44, 45]. In our study, KIOM-4 exhibited antioxidant effects by activating catalase, heme oxygenase-1, and manganese superoxide dismutase [1719]. In this context, the antidiabetic effects of KIOM-4 


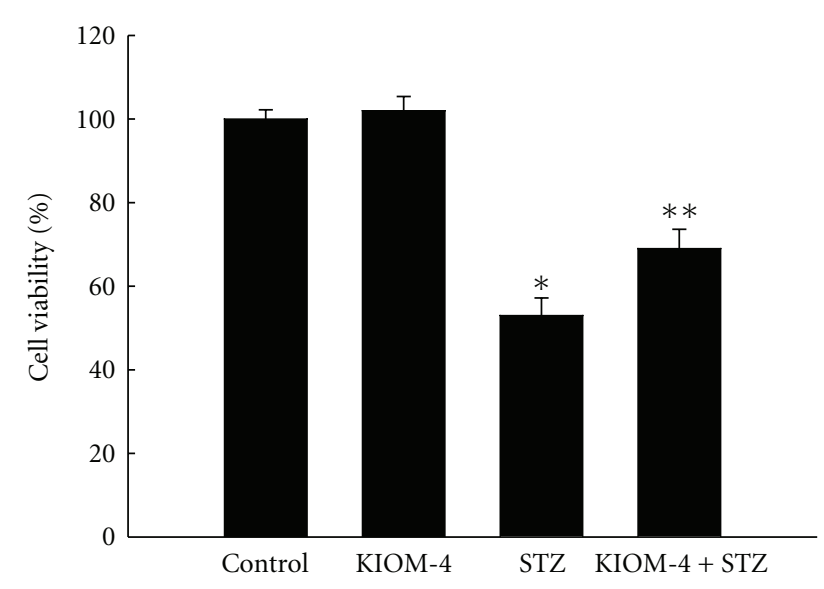

(a)
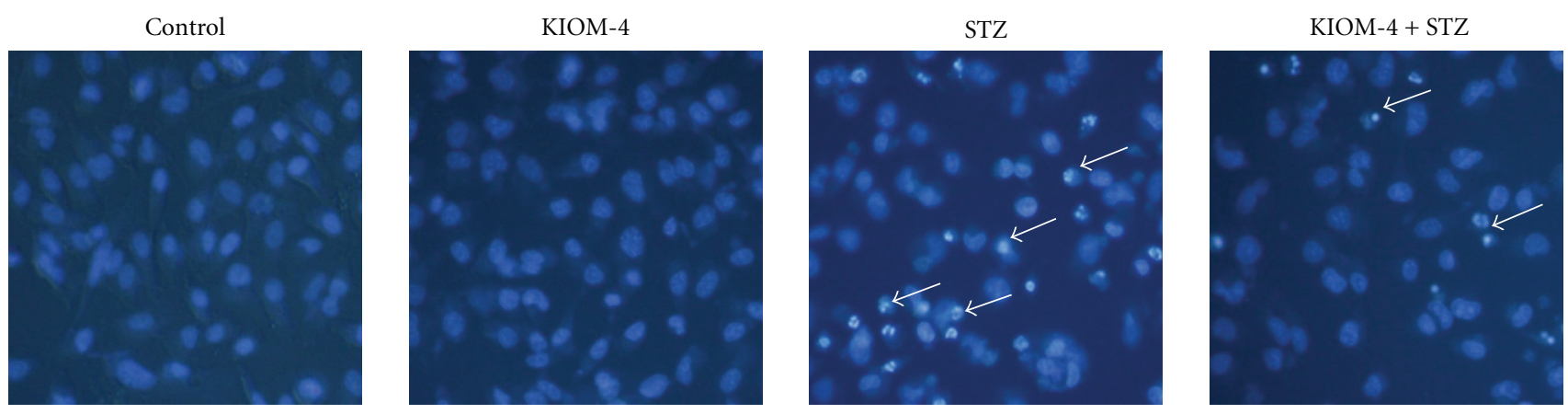

(b)

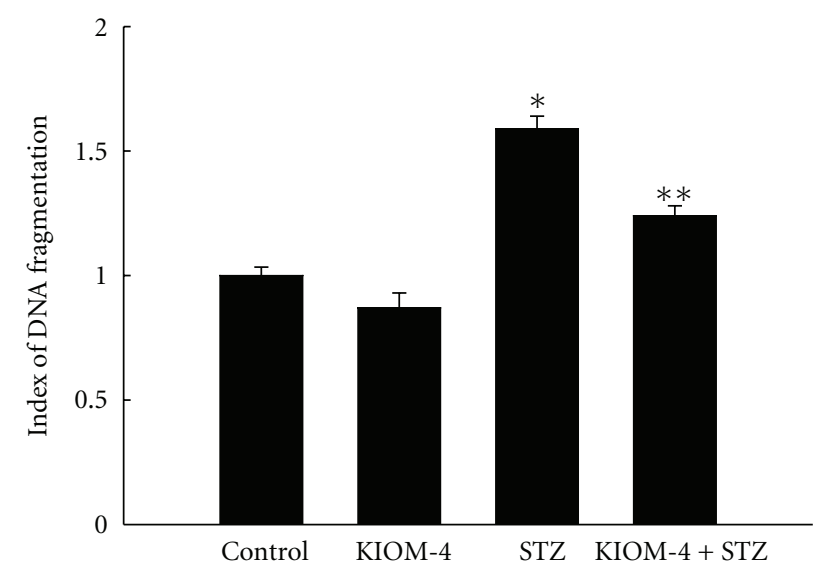

(c)

FIgURE 1: The effects of KIOM-4 on STZ-induced cell damage. RINm5F cells were treated with KIOM- 4 at $50 \mu \mathrm{g} / \mathrm{mL}$, after 1 hour, $10 \mathrm{mM}$ of STZ was added and was incubated for 24 hours. (a) Cell viability was measured using MTT assay. * Significantly different from control cells $(P<.05){ }^{* *}$ Significantly different from STZ-treated cells $(P<.05)$. (b) Apoptotic body formation was observed under a fluorescence microscope after Hoechst 33342 staining (original magnification, x400). Arrows indicate apoptotic bodies. (c) DNA fragmentation was quantified with an ELISA kit. Measurements were made in triplicate and the values are expressed as means \pm SEM. *Significantly different from control cells $(P<.05)$ and ${ }^{* *}$ significantly different from STZ-treated cells $(P<.05)$. 

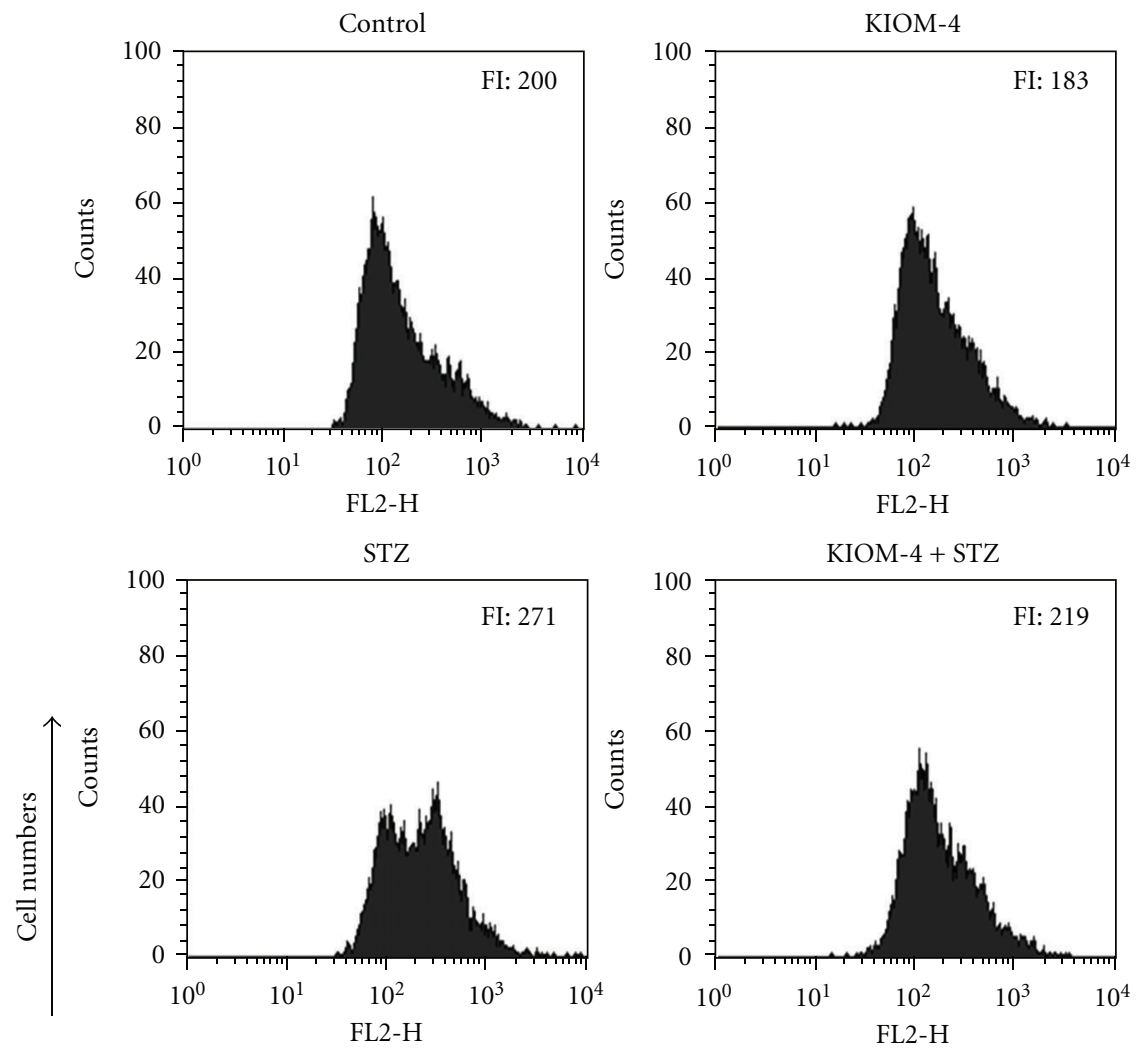

$\underset{\text { Increase of mitochondrial } \mathrm{Ca}^{2+}}{ }$

(a)
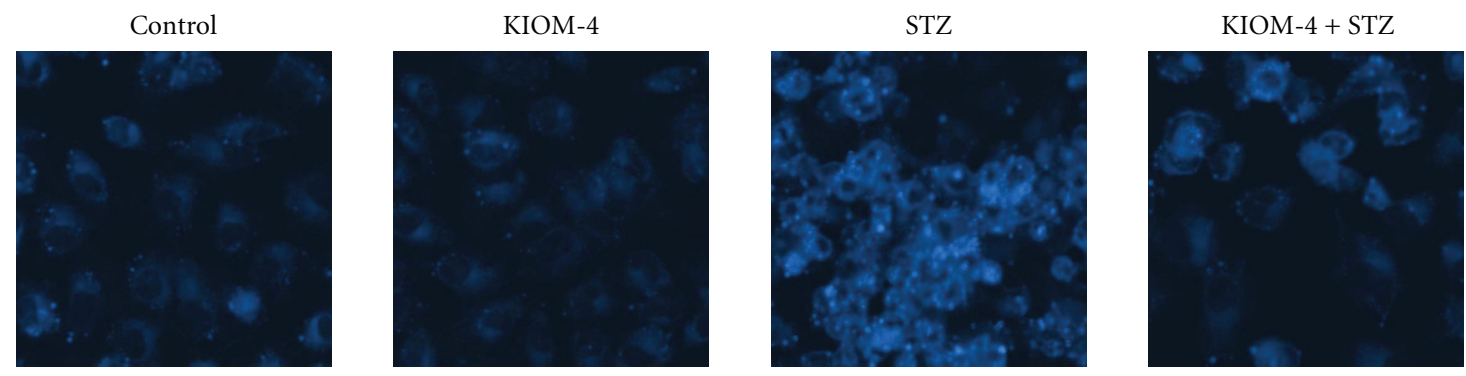

(b)
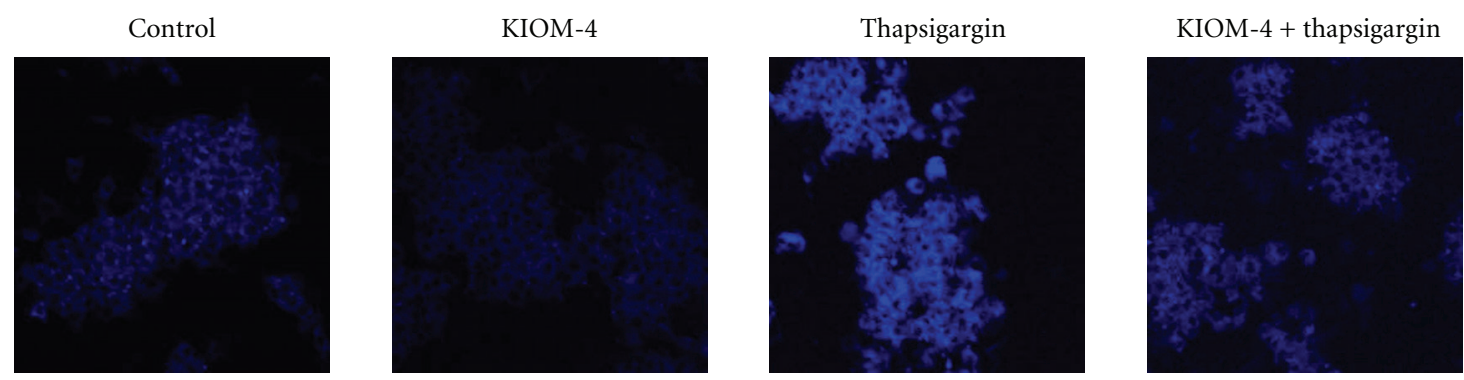

(c)

FIGURE 2: The effects of KIOM-4 on STZ-induced mitochondrial $\mathrm{Ca}^{2+}$ overloading and ER staining. Cells were treated with fluorescent probe Rhod-2 AM. The mitochondrial $\mathrm{Ca}^{2+}$ levels were measured by (a) flow cytometry as described in Section 2. FI indicates the fluorescence intensity of Rhod-2 AM. ((b) and (c)) Cells were treated with ER Tracker Blue-White DPX for ER staining as describe in Section 2. 

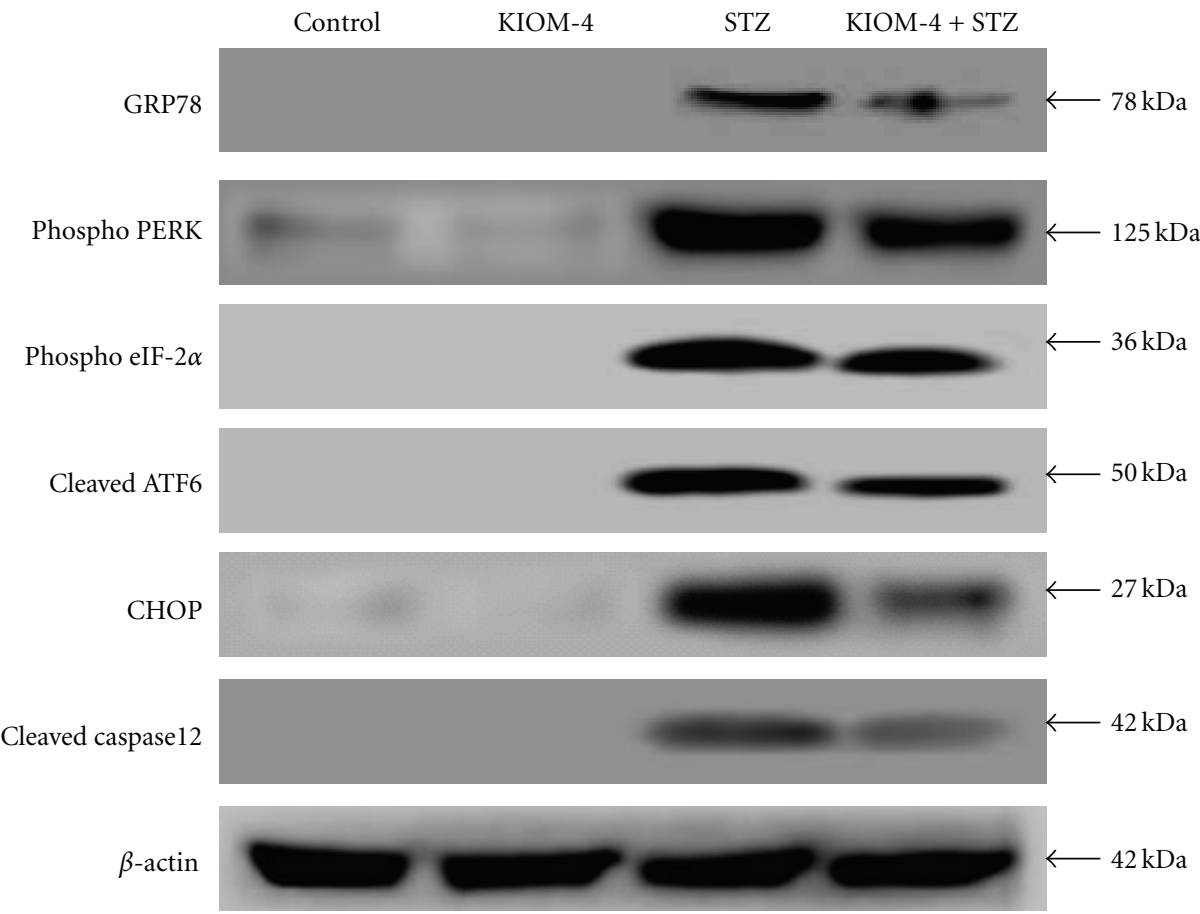

FIgURE 3: The effects of KIOM-4 on STZ-induced ER stress. The expression of GRP78, PERK and its downstream eIF-2 $\alpha$ phosphorylation as well as cleaved ATF6, capsase 12, and CHOP were determined by western blotting analysis.

on ER stress induced by STZ treatment in pancreatic $\beta$ cells were elucidated. Because elevation of mitochondrial $\mathrm{Ca}^{2+}$ levels or depletion of $\mathrm{ER} \mathrm{Ca}^{2+}$ stores is involved in ER stress-mediated apoptosis, we revealed that STZinduced mitochondrial $\mathrm{Ca}^{2+}$ overloading, indicating that alteration in $\mathrm{Ca}^{2+}$ homeostasis is implicated in STZ-induced apoptosis, while KIOM-4 treatment restored STZ-induced mitochondrial $\mathrm{Ca}^{2+}$ overloading. Moreover, recent studies suggest that increasing the fluorescent intensity following ER staining with ER-Tracker Blue-White DPX was considered a character of ER stress [37, 46]. In our study, STZ significantly increased the staining intensity of this dye, while KIOM4 attenuated the increased staining intensity. We further investigated specific markers of ER stress. The unfolded protein response of mammalian cells is initiated by three ER transmembrane proteins; PERK, IRE1, and ATF6. Many ER resident proteins display altered expression pattern under ER stress. Under unstressed conditions, the luminal domains of these sensors are occupied by the ER chaperon GRP78 [4749]. Upon ER stress, sequestration of GRP78 by unfolded proteins activates these sensors by inducing phosphorylation and homodimerization of PERK and IRE1, and relocation and proteolytic cleavage of ATF6 [45-47]. These three ER stress sensors trigger divergent and convergent signaling cascades, leading to adaptation or cell death [50]. Our study found that STZ-induced GRP78 release, PERK phosphorylation, and ATF6 cleavage while KIOM-4 inhibited these altered expression pattern in ER stress. Therefore, we speculated that the suppression of PERK phosphorylation and ATF6 cleavage by KIOM-4 treatment was mainly due to inhibition of GRP78 release. eIF-2 $\alpha$ is phosphorylated by
PERK in response to ER stress, leading to attenuation of translational initiation and protein synthesis [40, 41]. We also revealed that KIOM- 4 attenuated STZ-induced eIF- $2 \alpha$ phosphorylation. Caspase-12 has been reported to become activated during ER stress [35]. STZ treatment increases the activation of caspase-12 located in the cytoplasmic side of ER, while KIOM-4 inhibited caspase-12 activation [35]. CHOP protein was first identified to be a member of the CCAAT/enhancer binding proteins (C/EBPs) that dimerize with transcription factors C/EBP and Liver-enriched activation protein, and functions as a dominant-negative inhibitor of gene transcription [42]. CHOP is either not expressed or is expressed at low levels under physiological conditions, but is strongly induced in response to ER stress at the level of transcription [51]. Over-expression of CHOP leads to growth arrest and apoptosis [52-54]. CHOP knockout mice show normal development and fertility, but exhibit reduced apoptosis in response to ER stress [55-57]. Therefore, CHOP plays an important role in the induction of ER stressmediated apoptosis $[55,58]$. We observed that suppression of CHOP by CHOP siRNA attenuated STZ-induced apoptosis, suggesting that ER stress may be of importance for the cytotoxic activity of STZ. KIOM-4 treatment further reversed STZ-induced apoptosis in CHOP siRNA transfected cells, compared to control siRNA transfected cells. Hence, these results suggest that KIOM- 4 protects against STZ-induced apoptosis in diabetic pancreatic $\beta$-cells via inhibition of ER stress.

Taken together, this study demonstrated that KIOM-4 protected against STZ-induced $\beta$-cell damage via inhibition of ER stress-mediated apoptosis (Figure 5). 


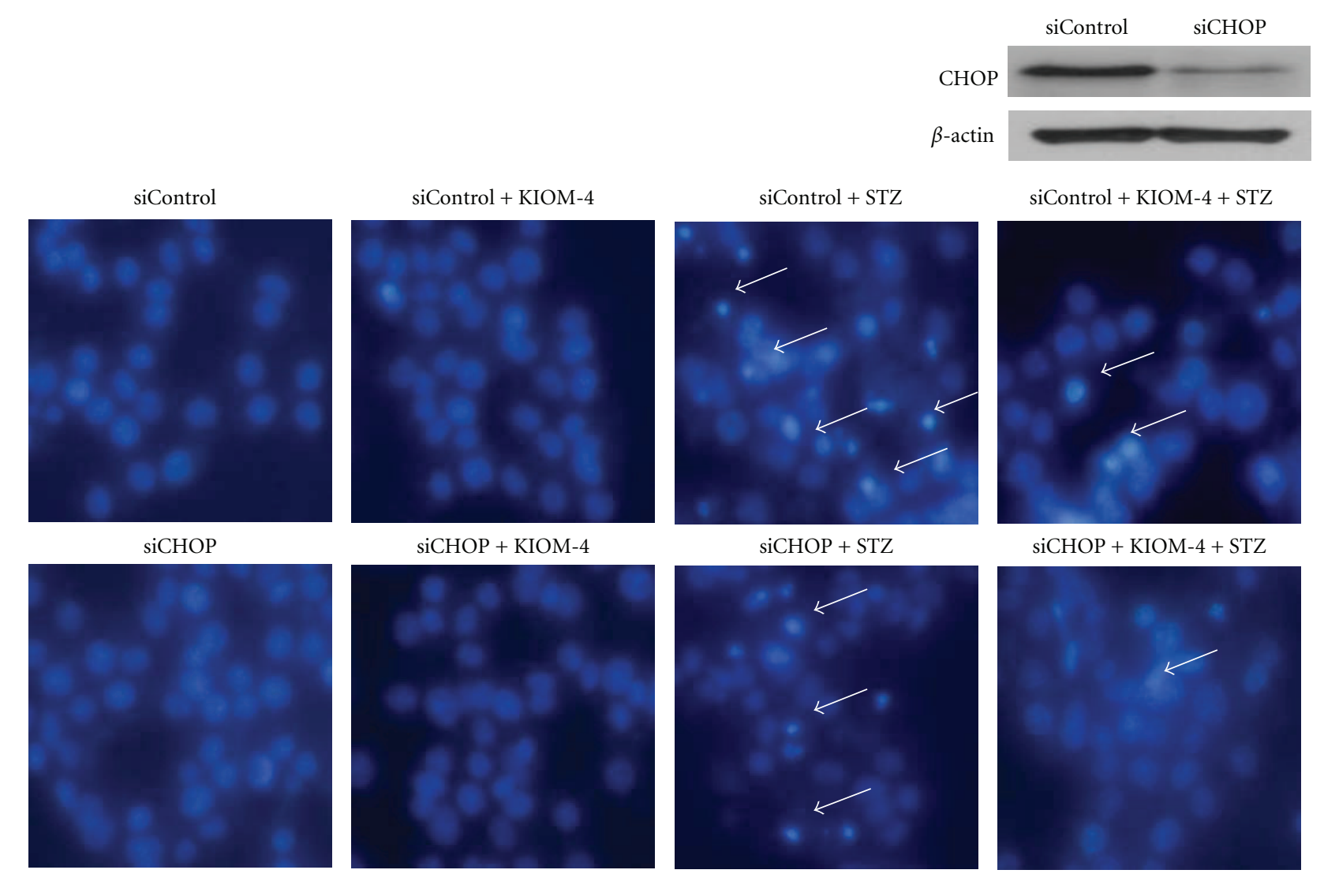

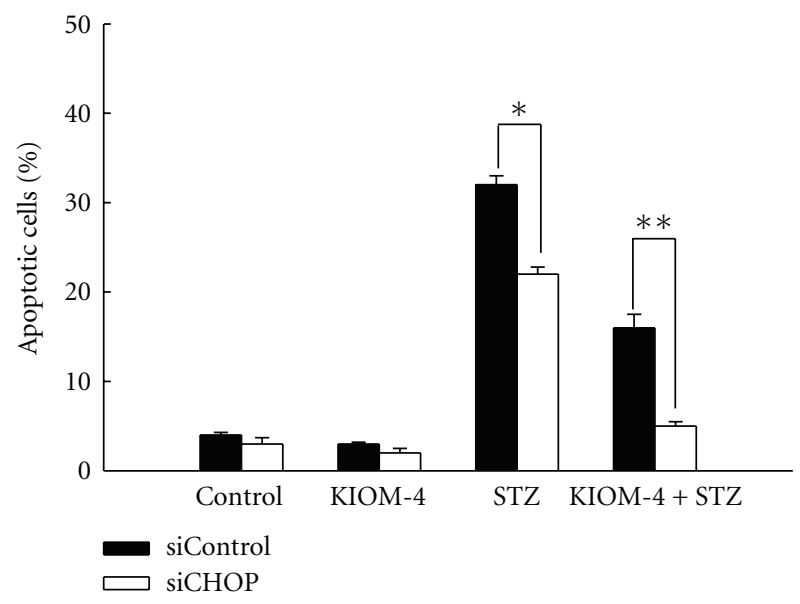

(a)

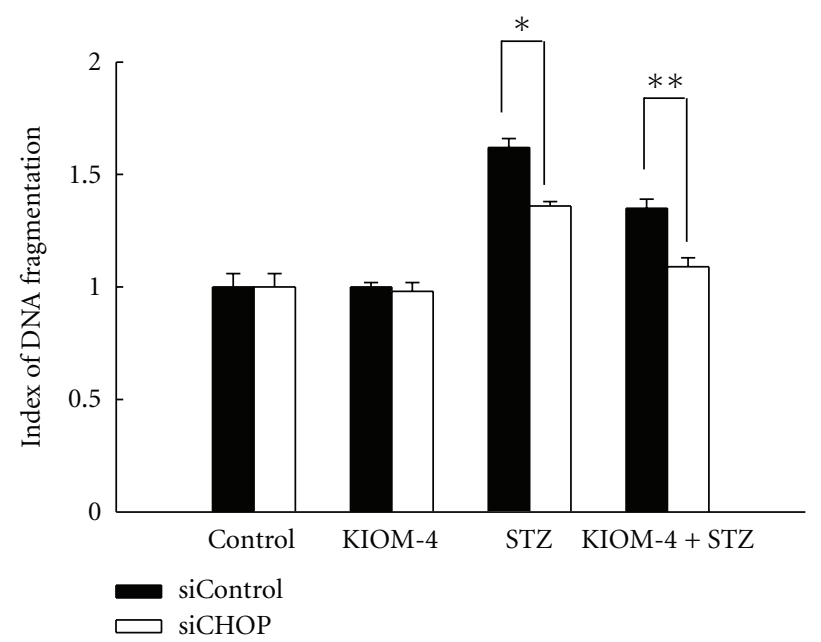

(b)

FIgURE 4: The effects of KIOM-4 on cell death induced by STZ in CHOP-downregulated cells. (a) Cells were transfected with CHOP siRNA or control siRNA, the transfected cells were treated with KIOM-4 at $50 \mu \mathrm{g} / \mathrm{mL}$. After 1 hour, $10 \mathrm{mM}$ of STZ was added and further incubated for 24 hours. (a) Apoptotic body formation was observed under a fluorescence microscope and quantitated after Hoechst 33342 staining (original magnification $\mathrm{x} 400$ ). Arrows indicate apoptotic bodies. ${ }^{*}$ Significantly different between STZ-treated siControl and STZ-treated siCHOP $(P<.05)$ and ${ }^{* *}$ significantly different between KIOM-4 plus STZ-treated siControl and KIOM-4 plus STZ-treated siCHOP cells $(P<.05)$. (b) DNA fragmentation was quantified with an ELISA kit. Measurements were made in triplicate and values are expressed as means \pm SEM. * Significantly different between STZ-treated siControl and STZ-treated siCHOP $(P<.05)$, and ${ }^{* *}$ significantly different between KIOM-4 plus STZ-treated siControl and KIOM-4 plus STZ-treated siCHOP cells $(P<.05)$. 


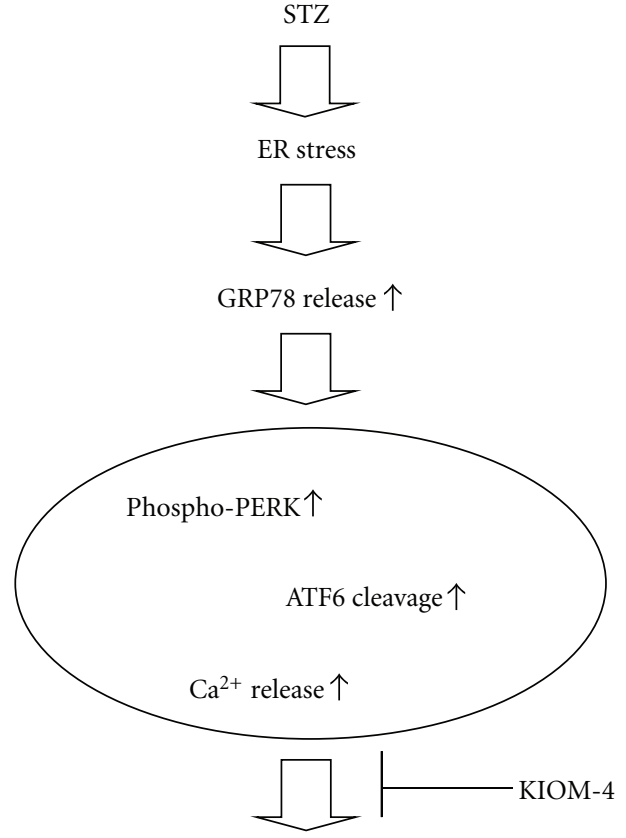

CHOP induction/caspase 12 activation

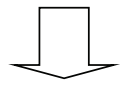

Apoptosis

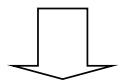

Loss of $\beta$-cell function

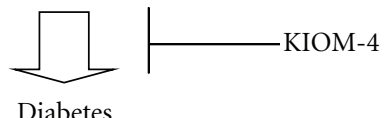

FIGURE 5: Model illustrating the inhibitory effect of KIOM-4 against STZ-induced ER stress pathway.

\section{Acknowledgment}

This paper was supported by a Grant (K10040) from the Korea Institute of Oriental Medicine. R. Zhang and J. S. Kim contributed equally to this study.

\section{References}

[1] J. Saito, Y. Sakai, and H. Nagase, "In vitro anti-mutagenic effect of magnolol against direct and indirect mutagens," Mutation Research, vol. 609, no. 1, pp. 68-73, 2006.

[2] E. J. Park, S. Y. Kim, Y. Z. Zhao, and D. H. Sohn, "Honokiol reduces oxidative stress, c-jun-NH2-terminal kinase phosphorylation and protects against glycochenodeoxycholic acid-induced apoptosis in primary cultured rat hepatocytes," Planta Medica, vol. 72, no. 7, pp. 661-664, 2006.

[3] A. H. Cao, L. T. Vo, and R. G. King, "Honokiol protects against carbon tetrachloride induced liver damage in the rat," Phytotherapy Research, vol. 19, no. 11, pp. 932-937, 2005.

[4] Y. R. Lin, H. H. Chen, C. H. Ko, and M. H. Chan, "Neuroprotective activity of honokiol and magnolol in cerebellar granule cell damage," European Journal of Pharmacology, vol. 537, no. 1-3, pp. 64-69, 2006.

[5] J. Lee, E. Jung, J. Park et al., "Anti-inflammatory effects of magnolol and honokiol are mediated through inhibition of the downstream pathway of MEKK-1 in NF- $\kappa$ B activation signaling," Planta Medica, vol. 71, no. 4, pp. 338-343, 2005.

[6] K. Y. Ho, C. C. Tsai, C. P. Chen, J. S. Huang, and C. C. Lin, "Antimicrobial activity of honokiol and magnolol isolated from Magnolia officinalis," Phytotherapy Research, vol. 15, no. 2, pp. 139-141, 2001.

[7] S. J. Lee, Y. H. Cho, K. Park et al., "Inhibitory effects of the aqueous extract of Magnolia officinalis on the responses of human urinary bladder cancer 5637 cells in vitro and mouse urinary bladder tumors induced by N-butyl-N-(4hydroxybutyl) nitrosamine in vitro," Phytotherapy Research, vol. 23, no. 1, pp. 20-27, 2009.

[8] W. Y. Tam, P. Chook, M. Qiao et al., "The efficacy and tolerability of adjunctive alternative herbal medicine (Salvia miltiorrhiza and Pueraria lobata) on vascular function and structure in coronary patients," Journal of Alternative and Complementary Medicine, vol. 15, no. 4, pp. 415-421, 2009.

[9] M. Miyazawa, K. Sakano, S. I. Nakamura, and H. Kosaka, "Antimutagenic activity of isoflavone from Pueraria lobata," Journal of Agricultural and Food Chemistry, vol. 49, no. 1, pp. 336-341, 2001.

[10] K. T. Lee, I. C. Sohn, D. H. Kim, J. W. Choi, S. H. Kwon, and H. J. Park, "Hypoglycemic and hypolipidemic effects of tectorigenin and kaikasaponin III in the streptozotocinlnduced diabetic rat and their antioxidant activity in vitro," Archives of Pharmacal Research, vol. 23, no. 5, pp. 461-466, 2000.

[11] K. T. Lee, I. C. Sohn, Y. K. Kim et al., "Tectorigenin, an isoflavone of Pueraria thunbergiana BENTH., induces differentiation and apoptosis in human promyelocytic leukemia HL-60 cells," Biological and Pharmaceutical Bulletin, vol. 24, no. 10, pp. 1117-1121, 2001.

[12] H. Liao, L. K. Banbury, and D. N. Leach, "Elucidation of Danzhixiaoyao Wan and its constituent herbs on antioxidant activity and inhibition of nitric oxide production," EvidenceBased Complementary and Alternative Medicine, vol. 4, no. 4, pp. 425-430, 2007.

[13] Z. Y. Wang and D. W. Nixon, "Licorice and cancer," Nutrition and Cancer, vol. 39, no. 1, pp. 1-11, 2001.

[14] D. G. Popovich, S. Y. Yeo, and W. Zhang, "Ginseng (Panax quinquefolius) and Licorice (Glycyrrhiza uralensis) root extract combinations increase hepatocarcinoma cell (Hep-G2) viability," Evidence-Based Complementary and Alternative Medicine. In press.

[15] M. J. Ahn, Y. K. Chul, S. L. Ji et al., "Inhibition of HIV1 integrase by galloyl glucoses from Terminalia chebula and flavonol glycoside gallates from Euphorbia pekinensis," Planta Medica, vol. 68, no. 5, pp. 457-459, 2002.

[16] L. Y. Kong, Y. Li, X. L. Wu, and Z. D. Min, "Cytotoxic diterpenoids from Euphorbia pekinensis," Planta Medica, vol. 68, no. 3, pp. 249-252, 2002.

[17] K. A. Kang, J. S. Kim, and J. W. Hyun, "KIOM-4 protects RINm5F pancreatic $\beta$-cells against streptozotocin induced oxidative stress in vitro," Biotechnology and Bioprocess Engineering, vol. 13, no. 2, pp. 150-157, 2008.

[18] K. A. Kang, J. S. Kim, R. Zhang et al., "Protective mechanism of KIOM-4 against streptozotocin induced diabetic cells: Involvement of heme oxygenase-1," Biotechnology and Bioprocess Engineering, vol. 14, no. 3, pp. 295-301, 2009. 
[19] K. A. Kang, J. S. Kim, and R. Zhang, "KIOM-4 protects against oxidative stress-induced mitochondrial damage in pancreatic $\beta$-cells via its antioxidant effects," Evidence-Based Complementary and Alternative Medicine. In press.

[20] D. Mathis, L. Vence, and C. Benoist, " $\beta$-cell death during progression to diabetes," Nature, vol. 414, no. 6865, pp. 792-798, 2001.

[21] E. V. Maytin and J. F. Habener, "Transcription factors $\mathrm{C} / \mathrm{EBP} \alpha$, $\mathrm{C} / \mathrm{EBP} \beta$, and CHOP (Gadd153) expressed during the differentiation program of keratinocytes in vitro and in vivo," Journal of Investigative Dermatology, vol. 110, no. 3, pp. 238-246, 1998.

[22] B. Heller, Z. Q. Wang, E. F. Wagner et al., "Inactivation of the poly(ADP-ribose) polymerase gene affects oxygen radical and nitric oxide toxicity in islet cells," The Journal of Biological Chemistry, vol. 270, no. 19, pp. 11176-11180, 1995.

[23] D. L. Eizirik and T. Mandrup-Poulsen, "A choice of deaththe signal-transduction of immune-mediated beta-cell apoptosis," Diabetologia, vol. 44, no. 12, pp. 2115-2133, 2001.

[24] K. Mori, "Tripartite management of unfolded proteins in the endoplasmic reticulum," Cell, vol. 101, no. 5, pp. 451-454, 2000.

[25] R. J. Kaufman, D. Scheuner, M. Schröder et al., "The unfolded protein response in nutrient sensing and differentiation," Nature Reviews Molecular Cell Biology, vol. 3, no. 6, pp. 411-421, 2002.

[26] S. Oyadomari, E. Araki, and M. Mori, "Endoplasmic reticulum stress-mediated apoptosis in pancreatic $\beta$-cells," Apoptosis, vol. 7, no. 4, pp. 335-345, 2002.

[27] E. Araki, S. Oyadomari, and M. Mori, "Endoplasmic reticulum stress and diabetes mellitus," Internal Medicine, vol. 42, no. 1, pp. 7-14, 2003.

[28] D. R. Laybutt, A. M. Preston, M. C. Åkerfeldt et al., "Endoplasmic reticulum stress contributes to beta cell apoptosis in type 2 diabetes," Diabetologia, vol. 50, no. 4, pp. 752-763, 2007.

[29] J. D. Malhotra, H. Miao, K. Zhang et al., "Antioxidants reduce endoplasmic reticulum stress and improve protein secretion," Proceedings of the National Academy of Sciences of the United States of America, vol. 105, no. 47, pp. 18525-18530, 2008.

[30] C. M. Haynes, E. A. Titus, and A. A. Cooper, "Degradation of misfolded proteins prevents ER-derived oxidative stress and cell death," Molecular Cell, vol. 15, no. 5, pp. 767-776, 2004.

[31] J. D. Malhotra, H. Miao, K. Zhang et al., "Antioxidants reduce endoplasmic reticulum stress and improve protein secretion," Proceedings of the National Academy of Sciences of the United States of America, vol. 105, no. 47, pp. 18525-18530, 2008.

[32] J. C. Wataha, C. T. Hanks, and R. G. Craig, "The in vitro effects of metal cations on eukaryotic cell metabolism," Journal of Biomedical Materials Research, vol. 25, no. 9, pp. 1133-1149, 1991.

[33] J. Carmichael, W. G. DeGraff, and A. F. Gazdar, "Evaluation of a tetrazolium-based semiautomated colorimetric assay: Assessment of chemosensitivity testing," Cancer Research, vol. 47, no. 4, pp. 936-942, 1987.

[34] G. Hajnoczky, L. D. Robb-Gaspers, M. B. Seitz, and A. P. Thomas, "Decoding of cytosolic calcium oscillations in the mitochondria," Cell, vol. 82, no. 3, pp. 415-424, 1995.

[35] S. B. Cullinan and J. A. Diehl, "Coordination of ER and oxidative stress signaling: the PERK/Nrf2 signaling pathway," International Journal of Biochemistry and Cell Biology, vol. 38, no. 3, pp. 317-332, 2006.

[36] J. Savory, M. M. Herman, and O. Ghribi, "Intracellular mechanisms underlying aluminum-induced apoptosis in rabbit brain," Journal of Inorganic Biochemistry, vol. 97, no. 1, pp. 151-154, 2003.
[37] M. Schröder and R. J. Kaufman, "The mammalian unfolded protein response," Annual Review of Biochemistry, vol. 74, pp. 739-789, 2005.

[38] K. F. Ferri and G. Kroemer, "Organelle-specific initiation of cell death pathways," Nature Cell Biology, vol. 3, no. 11, pp. E255-263, 2001.

[39] M. Abdelrahim, K. Newman, K. Vanderlaag, I. Samudio, and S. Safe, "3,3'-Diindolylmethane (DIM) and its derivatives induce apoptosis in pancreatic cancer cells through endoplasmic reticulum stress-dependent upregulation of DR5," Carcinogenesis, vol. 27, no. 4, pp. 717-728, 2006.

[40] H. Y. Jiang and R. C. Wek, "Phosphorylation of the $\alpha$-subunit of the eukaryotic initiation factor-2 (eIF $2 \alpha$ ) reduces protein synthesis and enhances apoptosis in response to proteasome inhibition," The Journal of Biological Chemistry, vol. 280, no. 14, pp. 14189-14202, 2005.

[41] M. Moenner, O. Pluquet, M. Bouchecareilh, and E. Chevet, "Integrated endoplasmic reticulum stress responses in cancer," Cancer Research, vol. 67, no. 22, pp. 10631-10634, 2007.

[42] S. Oyadomari and M. Mori, "Roles of CHOP/GADD153 in endoplasmic reticulum stress," Cell Death and Differentiation, vol. 11, no. 4, pp. 381-389, 2004.

[43] R. V. Rao, H. M. Ellerby, and D. E. Bredesen, "Coupling endoplasmic reticulum stress to the cell death program," Cell Death and Differentiation, vol. 11, no. 4, pp. 372-380, 2004.

[44] Y. Y. Jang, J. H. Song, Y. K. Shin, E. S. Han, and C. S. Lee, "Protective effect of boldine on oxidative mitochondrial damage in streptozotocin-induced diabetic rats," Pharmacological Research, vol. 42, no. 4, pp. 361-371, 2000.

[45] L. Zhang, A. Zalewski, Y. Liu et al., "Diabetes-induced oxidative stress and low-grade inflammation in porcine coronary arteries," Circulation, vol. 108, no. 4, pp. 472-478, 2003.

[46] J. H. Lim, J. W. Park, S. H. Kim, Y. H. Choi, K. S. Choi, and T. K. Kwon, "Rottlerin induces pro-apoptotic endoplasmic reticulum stress through the protein kinase C- $\delta$-independent pathway in human colon cancer cells," Apoptosis, vol. 13, no. 11, pp. 1378-1385, 2008.

[47] H. P. Harding, M. Calfon, F. Urano, I. Novoa, and D. Ron, "Transcriptional and translational control in the mammalian unfolded protein response," Annual Review of Cell and Developmental Biology, vol. 18, pp. 575-599, 2002.

[48] K. Zhang and R. J. Kaufman, "Signaling the unfolded protein response from the endoplasmic reticulum," The Journal of Biological Chemistry, vol. 279, no. 25, pp. 25935-25938, 2004.

[49] M. Schröder and R. J. Kaufman, "The mammalian unfolded protein response," Annual Review of Biochemistry, vol. 74, pp. 739-789, 2005.

[50] J. Wu and R. J. Kaufman, "From acute ER stress to physiological roles of the unfolded protein response," Cell Death and Differentiation, vol. 13, no. 3, pp. 374-384, 2006.

[51] X. Z. Wang, B. Lawson, J. W. Brewer et al., "Signals from the stressed endoplasmic reticulum induce C/EBP-homologous protein (CHOP/GADD153)," Molecular and Cellular Biology, vol. 16, no. 8, pp. 4273-4280, 1996.

[52] M. V. Barone, A. Crozat, A. Tabaee, L. Philipson, and D. Ron, "CHOP (GADD153) and its oncogenic variant, TLS-CHOP, have opposing effects on the induction of G1/S arrest," Genes and Development, vol. 8, no. 4, pp. 453-464, 1994.

[53] M. Matsumoto, M. Minami, K. Takeda, Y. Sakao, and S. Akira, "Ectopic expression of CHOP (GADD153) induces apoptosis in M1 myeloblastic leukemia cells," FEBS Letters, vol. 395, no. 2-3, pp. 143-147, 1996. 
[54] T. Gotoh, S. Oyadomari, K. Mori, and M. Mori, "Nitric oxideinduced apoptosis in RAW 264.7 Macrophages is mediated by endoplasmic reticulum stress pathway involving ATF6 and CHOP," The Journal of Biological Chemistry, vol. 277, no. 14, pp. 12343-12350, 2002.

[55] H. Zinszner, M. Kuroda, X. Wang et al., "CHOP is implicated in programmed cell death in response to impaired function of the endoplasmic reticulum," Genes and Development, vol. 12, no. 7, pp. 982-995, 1998.

[56] S. Oyadomari, K. Takeda, M. Takiguchi et al., "Nitric oxideinduced apoptosis in pancreatic $\beta$-cells is mediated by the endoplasmic reticulum stress pathway," Proceedings of the National Academy of Sciences of the United States of America, vol. 98, no. 19, pp. 10845-10850, 2001.

[57] S. Oyadomari, A. Koizumi, K. Takeda et al., "Targeted disruption of the Chop gene delays endoplasmic reticulum stress-mediated diabetes," The Journal of Clinical Investigation, vol. 109, no. 4, pp. 525-532, 2002.

[58] S. C. Pino, B. O’Sullivan-Murphy, E. A. Lidstone et al., “CHOP mediates endoplasmic reticulum stress-induced apoptosis in Gimap5-deficient T cells," PLoS ONE, vol. 4, no. 5, Article ID e5468, 2009. 


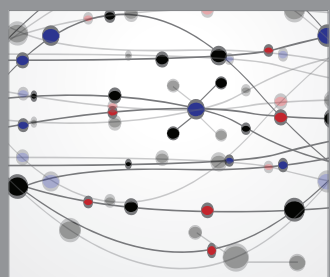

The Scientific World Journal
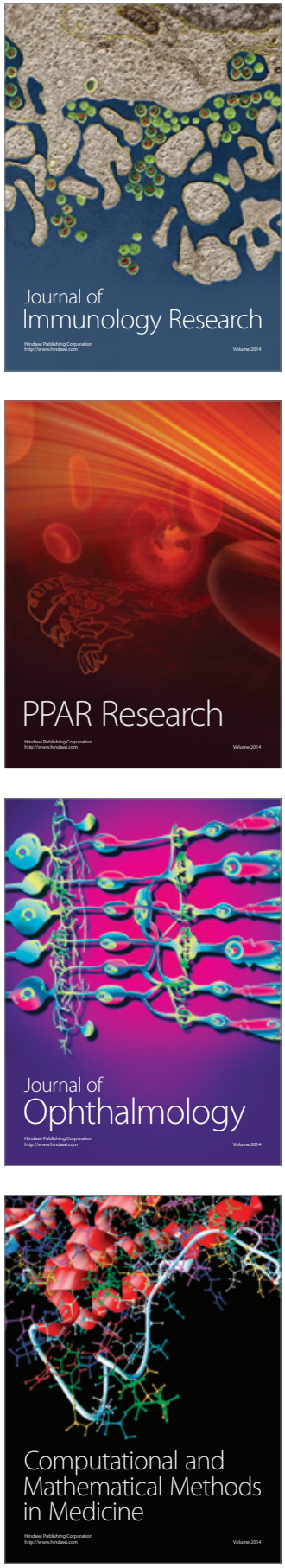

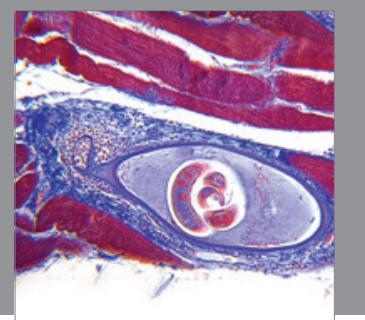

Gastroenterology

Research and Practice
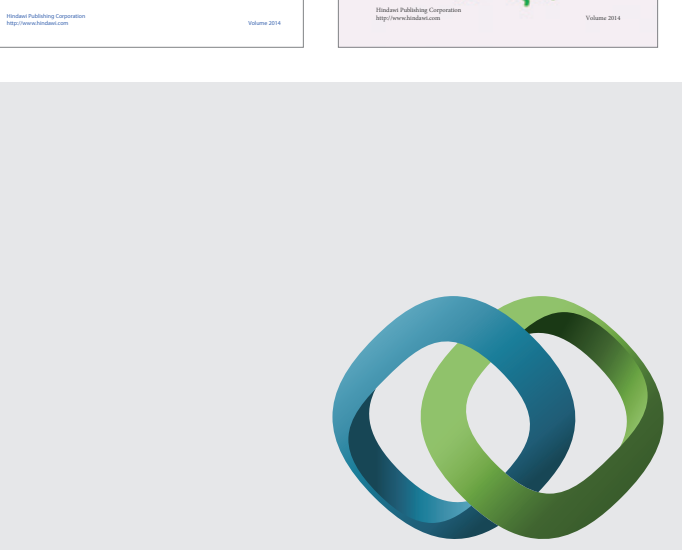

\section{Hindawi}

Submit your manuscripts at

http://www.hindawi.com
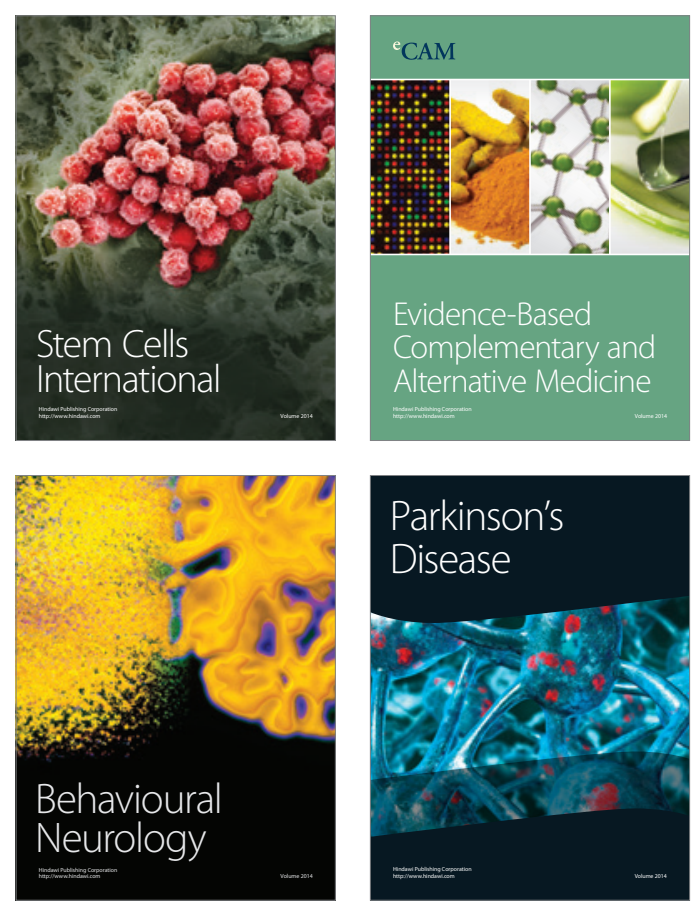

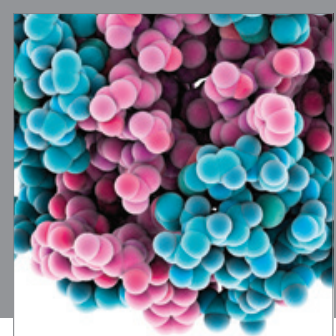

Journal of
Diabetes Research

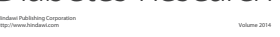

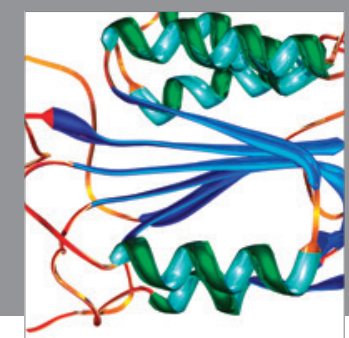

Disease Markers
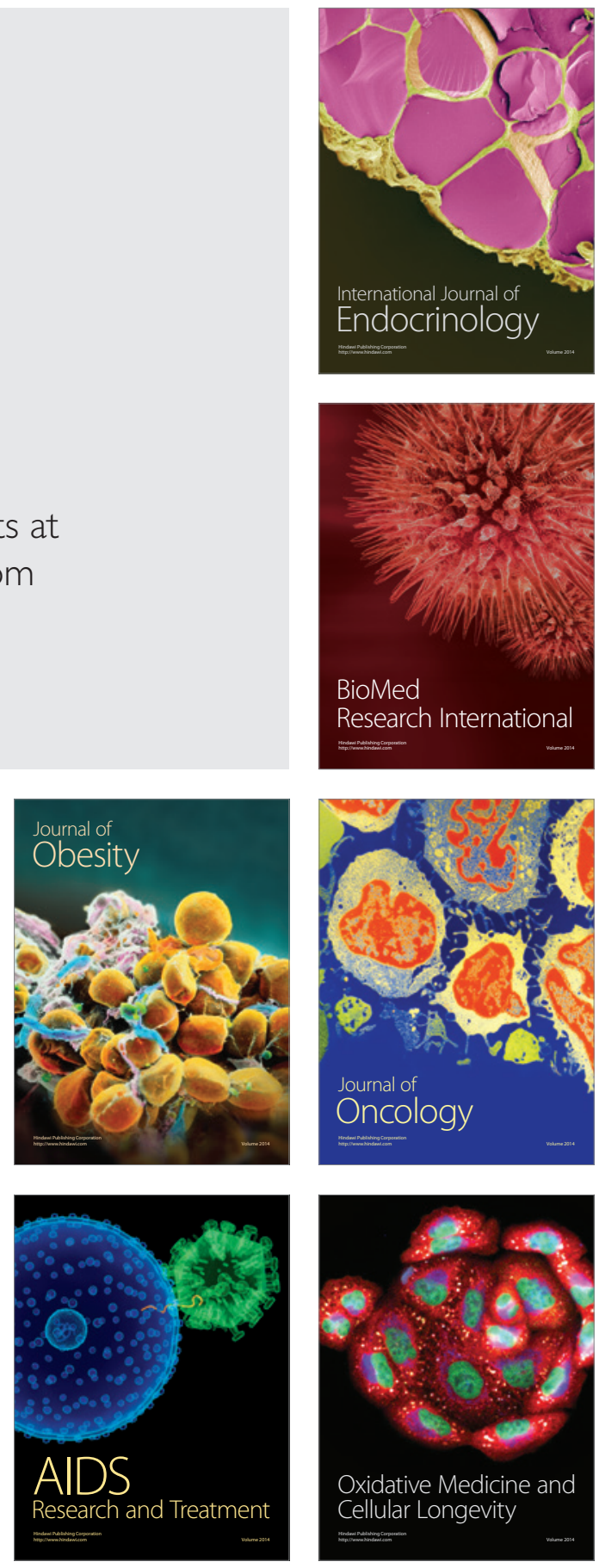